\title{
Erratum to: On perturbation theory and critical exponents for self-similar systems
}

\author{
Ehsan Hatefi ${ }^{\mathrm{a}}$, Adrien Kuntz ${ }^{\mathrm{b}}$ \\ Scuola Normale Superiore and I.N.F.N., Piazza dei Cavalieri 7, 56126 Pisa, Italy
}

Received: 19 January 2022 / Accepted: 29 January 2022 / Published online: 14 February 2022

(C) The Author(s) 2022

Erratum to: Eur. Phys. J. C (2021) 81:15

$$
\text { https://doi.org/10.1140/epjc/s10052-020-08788-w }
$$

ArXiv e-Print: arXiv:2010.11603

Author Ehsan Hatefi has just the following affiliation:

Scuola Normale Superiore and I.N.F.N., Piazza dei Cavalieri 7, 56126, Pisa, Italy

The original article has been corrected.
Open Access This article is licensed under a Creative Commons Attribution 4.0 International License, which permits use, sharing, adaptation, distribution and reproduction in any medium or format, as long as you give appropriate credit to the original author(s) and the source, provide a link to the Creative Commons licence, and indicate if changes were made. The images or other third party material in this article are included in the article's Creative Commons licence, unless indicated otherwise in a credit line to the material. If material is not included in the article's Creative Commons licence and your intended use is not permitted by statutory regulation or exceeds the permitted use, you will need to obtain permission directly from the copyright holder. To view a copy of this licence, visit http://creativecomm ons.org/licenses/by/4.0/.

Funded by SCOAP ${ }^{3}$.

The original article can be found online at https://doi.org/10.1140/ epjc/s10052-020-08788-w.

a e-mail: ehsan.hatefi@sns.it (corresponding author)

be-mail: adrien.kuntz@sns.it 